\title{
Corona brengt digitale zorg in stroomversnelling
}

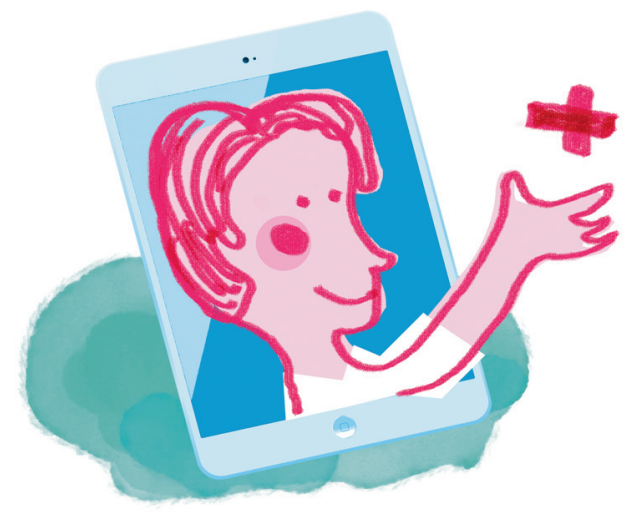

Corona is een vliegwiel voor digitale toepassingen in de zorg. Maar blijven patiënten en zorgverleners beeldbellen, telebegeleiding en apps omarmen als de coronapandemie voorbij is?

tekst Margot Hamel illustratie Bernet Ragetli

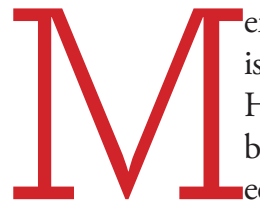

eneer Van Ommeren is bang voor corona. Hij is $70+$, heeft diabetes, hypertensie en verpleegkundigen van ulcus cruris. Of de blieft willen wegblijven? Hij wacht alles liever rustig af.

Nu zoekt de wijkverpleegkundige naar een oplossing. Ze denkt aan het inzetten van de Google Glass, de bril met camera waarmee de wondverpleegkundige kan meekijken met meneer. Eerder had ze hier niet aan gedacht.

\section{Toename e-health}

De invloed van covid-19 op het gebruik van e-health - zoals beeldbellen, telebegeleiding, het gebruik van apps en brillen als Google glass - is groot, constateert Marian Adriaansen, lector innovatie in de care aan de HAN (Hogeschool Arnhem Nijmegen). 'Er zijn veel digitale initiatieven uitgebouwd of opgestart. Zelf onderzoeken we in een aantal wijken in de regio Nijmegen de ervaringen van paramedici, verpleegkundigen en cliënten in de wijk met digitale zorg, en welke toepassingen zij willen blijven gebruiken. Want voor corona verliep de digitalisering nogal moeizaam. We zijn benieuwd of er bij zorgverleners en cliënten een knop is omgezet. Ik hoop het.' Adriaansen verwacht de resultaten in december te publiceren.

\section{Beeldbellen populair}

Er zijn nog geen landelijke gegevens bekend over de toename van het gebruik van de digitale middelen. Maar de Raad voor de Volksgezondheid \& Samenleving (RVS) verzamelde deze zomer informatie hierover uit enquêtes, peilingen, en praktijkervaringen. Zo bleek uit een enquête van NIVEL onder 1.000 huisartsen dat tijdens de eerste coronagolf $64 \%$ voor het eerst gebruikmaakte van beeldbellen, en dat 53\% dat wil blijven doen. Datzelfde blijkt uit een onderzoek onder medisch specialisten. ${ }^{1}$

In Vlaanderen was 99\% van de deelnemende huisartsen aan een enquête van huisartsenvereniging Domus Medica enthousiast over telefonische consultaties, maar minder over videobellen (29\%). ${ }^{2}$ Toch ziet $58 \%$ van alle respondenten zichzelf in de nabije toekomst vaker bellen én videobellen. ${ }^{3}$

\section{Telebegeleiding}

De RVS kwam erachter dat vooral beeldbellen veel vaker werd toegepast. Richard Heijink: 'Medisch en verpleegkundig specialisten gebruikten daarnaast vaker telebegeleiding. Het is niet vreemd dat beeldbellen een vlucht nam, want het is sneller op te zetten dan telebegelei-

\section{'Als we over 15 jaar terugkijken, dan lachen we om hoe moeilijk we deden over de inzet van digitale zorg'}




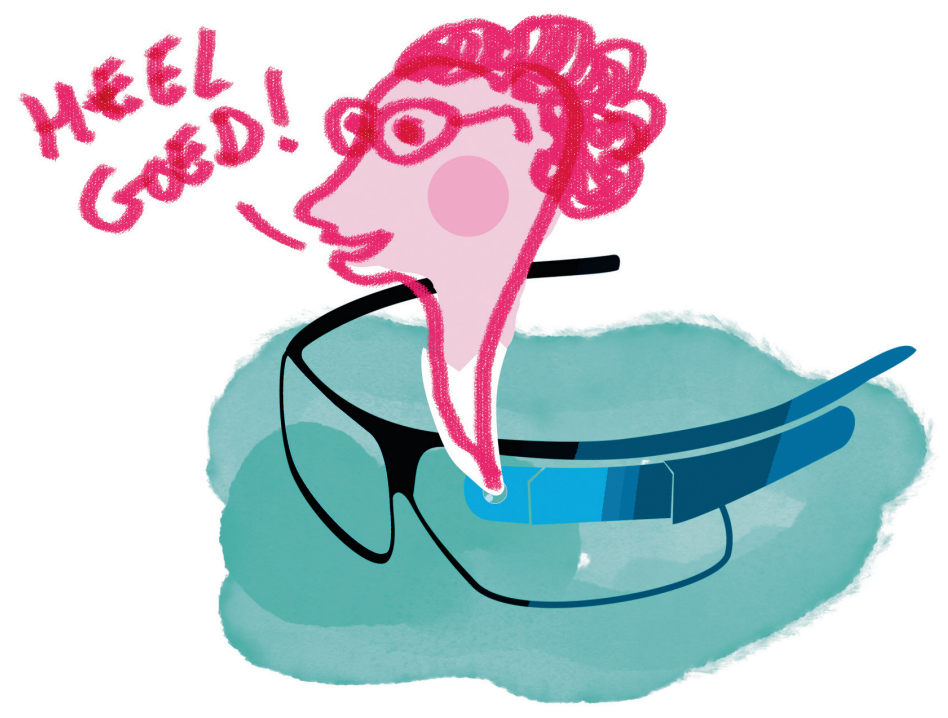

ding.' Bij dat laatste meten patiënten thuis zelf hun waardes en delen die via een app of online met hun zorgverlener. COPD-patiënten van OLVG in Amsterdam beantwoorden bijvoorbeeld via het online programma OLVG COPD Coach vragen over hun gezondheid en welzijn. Een longverpleegkundige neemt contact op als de score te hoog wordt.' 750 van de 1.800 COPD-patiënten willen er desgevraagd aan meedoen in deze coronatijd. ${ }^{3}$

\section{Uitbouwen}

In de meest gevallen is er vooral voortgeborduurd op wat er al was. 'Dat is logisch, omdat zorgverleners in korte tijd oplossingen moesten zoeken', vindt Richard Heijink. 'Aanbieders die al actief met digitale zorg bezig waren, hadden dan ook een voorsprong.' Zo zet Sensire (organisatie voor thuiszorg en langdurige zorg in het oosten van het land) al jaren digitale zorg in. Dochteronderneming NAAST kreeg tijdens de eerste coronagolf 600 nieuwe beeldzorgklanten.

Kim Tijdink is wijkverpleegkundige bij Sensire Lochem, met digitale zorg als aandachtspunt. 'NAAST is een medisch servicecentrum waar verpleegkundigen en verzorgenden op afstand zorg leveren. De klanten krijgen een Compaan in bruikleen: een speciaal voor ouderen ontwikkelde tablet (met een beperkt aantal knoppen) die aan het begin van de coronacrisis voor het eerst werd ingezet. De klanten praten via deze tablet met de zorgmedewerker en zien haar ook. Zo kan de medewerker meekijken met bijvoorbeeld medicatie-inname, stomazorg,

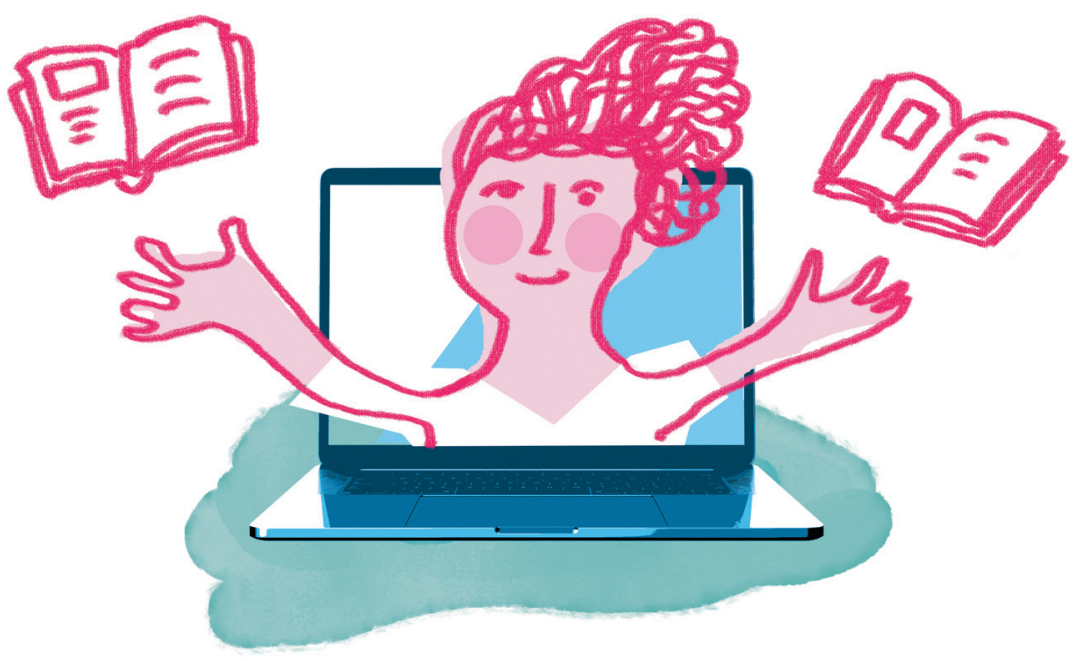

\section{WEG THEIMA-AVOND, WELKOIM WEBINAR}

$\mathrm{N}$ a de eerste coronagolf organiseerde Geertruida van Harten met collega's een thema-avond in het kader van het afdelingsproject 'Verbeteren van de psychosociale zorg'. Ze werkt als senior verpleegkundige op de afdeling MDL van ziekenhuis Rijnstate in Arnhem.

Maar toen de tweede coronagolf kwam, besloten ze er een webinar van te maken 'want het samen leren is belangrijk.' Via de audiovisuele afdeling leerden ze hoe ze dat moesten opzetten. 'De powerpoint-presentatie deelden we via Teams, en de casussen bespraken we met zijn allen.' Klinkt niet moeilijk, maar toch had het heel wat voeten in de aarde. 'Verpleegkundigen hoefden nooit Teams te gebruiken, en sommigen hebben moeite met digitale oplossingen. Daarom ruimden we een half uur in voor extra uitleg.' Uiteindelijk deden meer collega's mee dan aan een thema-avond of werkoverleg. 'Je hoeft nu niet in je vrije tijd naar het ziekenhuis te komen, maar logt in vanuit huis, dat scheelt tijd en inspanning. We willen het ook gaan inzetten voor klinische lessen. Corona is verschrikkelijk, maar zonder hadden we dit niet uitgezocht. Het wijst ons ook op de noodzaak van het bijhouden van onze digitale vaardigheden.'

en het instellen van een insulinepen.'

NAAST levert ook videozorg. 'Bijvoorbeeld via cameramonitoring bij een thuiswonende oudere met dementie die's nachts onrustig is. Een nachtelijk bezoek om de situatie te beoordelen is zo niet meer nodig, en de klant wordt niet gestoord.'

\section{Ervaringen positief}

Voor de coronacrisis was er nogal wat scepsis tegen zorg op afstand, zowel bij de klanten als bij verpleegkundigen, merkte Kim Tijdink: 'Klanten - en ook hun omgeving - denken vaak dat ze als 
CLL van loghum

CSS bohn 7) stafleu

1. van loghum

cce bohn

9 stafleu

CL van loghum

cCe bohn

stafleu
van loghum

cCohn bohn

D) stafleu

van loghum

$\int S$ bohn

C. van loghum

cCe bohn

9) stafleu

van loghum

SCS bohn

CL van loghum

CSS bohn

¿stafleu van loghum

SSS bohn

van loghum
\& stafleu

van loghum

$\iint \begin{aligned} & \text { bohn } \\ & \text { stafleu } \\ & \text { van loghur }\end{aligned}$

van loghum

SSS $\begin{aligned} & \text { bohn } \\ & \text { stafleu }\end{aligned}$

van loghum

CSS bohn

stafleu

van loghum

$\int S$ bohn

1. van loghum

CSS bohn

stafleu

$\int S$ bohn

van loghum

SCS bohn

stafleu

van loghum

CS bohn

stafleu

CS bohn

CL van loghum

SCS bohn

stafleu

van loghum

SCS bohn

8 stafleu

van loghum

$\iint \begin{aligned} & \text { bohn } \\ & \text { stafleu } \\ & \text { van loghum }\end{aligned} \quad$ SC $\begin{aligned} & \text { bohn } \\ & \text { stafleu } \\ & \text { van loghum }\end{aligned}$
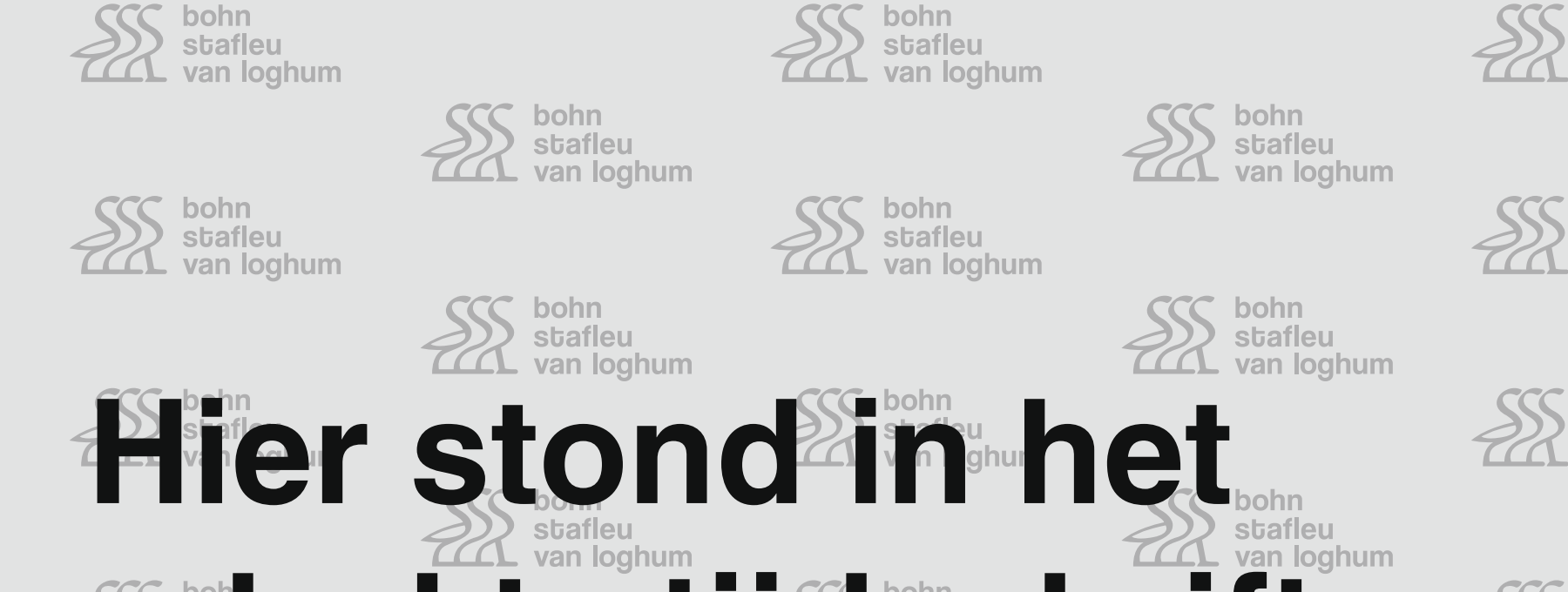

CSS bohn

Psafleu

van loghum

CSS bohn

8 stafleu

cL van loghum

SSS bohn

8 L van loghum

CSS bohn

$8 \int$ stafleu

1. van loghum

SSS bohn

CL van loghum

CSS bohn

S) stafleu

SSS bohn

van loghum

CCS bohn

S) stafleu

CL van loghum bohn

stafleu

van loghum

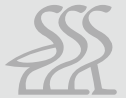

SCS bohn

SS stafleu van loghum

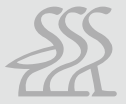

CSS bohn

stafleu

van loghum

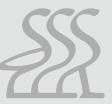

CSS bohn

S) stafleu van loghum

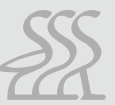

SSS bohn van loghum 


\section{DIGITAAL DANKZIJ CORONA}

Z

orgverleners werden creatief tijdens de eerste lockdown.

Een greep uit de initiatieven:

Corona Check app: in korte tijd door meer dan 170.000 mensen buiten het ziekenhuis gebruikt om op afstand gezondheidsgegevens gerelateerd aan corona te kunnen monitoren.

- 'Covid-box' van het Leids Universitair Medisch Centrum (LUMC), met een digitale thermometer, een bloeddruk- en een saturatiemeter. Ontslagen covidpatiënten geven de metingen door tijdens een videoconsult. Het LUMC werkt nog aan een app die de metingen automatisch registreert en doorgeeft.

- Virtueel revalidatieprogramma voor coronapatiënten, Diakonessenhuis Utrecht. Patiënten treden via een VR-bril een andere omgeving binnen, met als doel hersenen te prikkelen en herstel te bevorderen.

- Telebegeleiding (vooral bij chronische aandoeningen zoals COPD, diabetes en hartfalen): ziekenhuizen die er al mee bezig waren, zoals Tergooi ziekenhuizen (regio Hilversum), Isala Zwolle, Alrijne Ziekenhuis (regio Leiden) en Maastricht UMC+, zijn het meer gaan inzetten.

- Slingelandziekenhuis in Doetinchem: versnelde invoering van continue monitoring van vitale functies.

- Slimme pleister op de borst om op afstand onder andere hartslag en ademfrequentie van covid-patiënten te monitoren (UMC Utrecht).

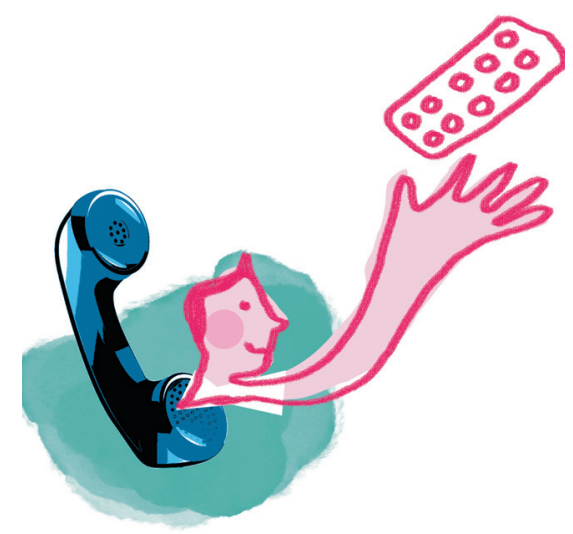

80-plusser nooit een tablet kunnen leren bedienen.' Toch zijn de gebruikers in het algemeen positief, constateert Tijdink: 'Ze waarderen de spelletjes op de tablet en dat ze toch contact kunnen hebben met familie, zelfs vaker dan voor corona. Maar fysieke ontmoetingen blijven natuurlijk belangrijk. Na de eerste coronagolf gaven de meeste gebruikers aan de Compaanzorg te willen behouden, al dan niet in combinatie met bezoek van de zorgverlener, een enkeling wilde alleen fysieke ontmoetingen.'

\section{Transitieperiode}

De ervaringen zijn dus overwegend positief, maar zal de digitale zorg in zijn algemeenheid na corona beklijven? 'Ik denk dat we in een transitieperiode zitten', antwoordt lector Marian Adriaansen. 'Als we over 15 jaar terugkijken, dan lachen we om hoe moeilijk we deden over de inzet van digitale zorg. Veel verpleegkundigen denken nog steeds dat oudere cliënten meer zien in dagelijkse bezoeken van zorgverleners dan in tabletzorg. Dat je als cliënt de dag beter zelf kunt indelen dankzij de tabletzorg, dat zit nog niet in ons zorgverleners-DNA. Wij willen "mensen helpen" en dat doe je door fysiek bij hen te zijn. Maar er is een omslag in denken nodig. Met het oog op het verwachte tekort aan verpleegkundigen en verzorgenden moeten we zorg aanbieden die meer gericht is op digitale vervanging. In de wijk is nog veel tijd te besparen door videozorg en beeldbellen. Al die reistijd kunnen we missen.'

Bij Sensire zijn ze hier al mee begonnen, vertelt Kim Tijdink. 'Bij elke indicatiestelling vraag ik "Wat heeft u nodig", en vervolgens bekijk ik of de hulpvraag digitaal ingevuld kan worden. Dat is een andere manier van denken.'

\section{Andere financiering}

Volgens Marian Adriaansen is er ook voor de zorgverzekeraars werk aan de winkel. 'Het slagen van digitale zorg staat of valt met de juiste financiering. Maar zorgverzekeraars willen altijd eerst behoefteonderzoek en bewijs dat iets werkt. Door corona werden ook zij gedwongen
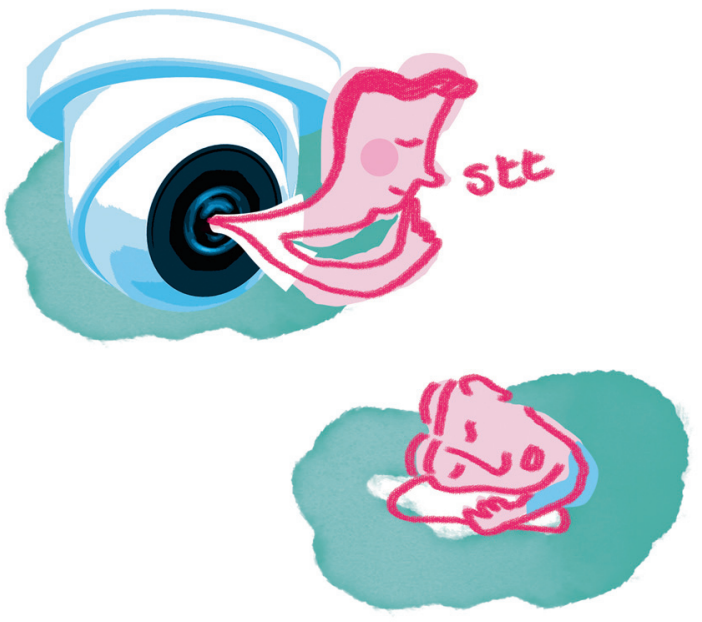

te schakelen. Zij hebben tijdelijk nieuwe vormen van zorgverlenen vergoed, zoals beeldbellen. Ook kwam de overheid met coronasubsidies, om op korte termijn digitale coronazorg te ontwikkelen. Maar nu moeten we doorpakken en bepalen wat er na de coronacrisis wordt vergoed en hoe dat wordt ingericht. Want ik weet zeker dat beeldbellen en videozorg veel vaker toegepast zullen worden. Er zijn nu zoveel zorgverleners en patiënten die ermee hebben kennisgemaakt, en die de voordelen ervan inzien. Mijn advies aan verpleegkundigen zou zijn: is de digitale zorg (bijna) goed bevallen, ontwikkel het door, verbeter het proces en maak het duurzaam. De Google Glass kwam onder druk van corona bijvoorbeeld terug voor het meekijken bij wondzorg. Als dat bevalt, waarvoor zou je het nog meer kunnen inzetten, en wat heb je daarvoor nodig? Als verpleegkundige kun je zo zelf actief bijdragen aan vernieuwing van de zorg. Als dat geen verpleegkundig leiderschap is!'

Noten

1 Raad van Volksgezondheid en Samenleving. Zorg op afstand dichterbij? Digitale zorg na de coronacrisis. Den Haag, augustus 2020. Zie www.raadrvs.nl, zoek op titel van het rapport.

2 Domus Medica. Teleconsultatie bij de huisarts. Een survey onder huisartsen naar ervaringen in gebruik en perspectieven voor de toekomst. 29 oktober 2020 .

3 Ook het RIZIV ondervroeg beroepsgroepen, waaronder diabeteseducatoren, maar bij het ter perse gaan van dit nummer waren de resultaten nog niet bekend. Ter zijner tijd staan deze op: https://www.inami.fgov.be, zoek op 'bevraging zorg op afstand'

4 www.olvg.nl/nieuws/al-bijna-650-copd-patienten-van-olvg-krijgen-nu-thuis-ondersteuning-met-digitale-coach. 